III.

\title{
Theoretische Berechnung
}

\section{einer \\ Schleuderpumpe \\ auf Grund von Versuchen.}

Von

H. C. A. LUDEWIG

Professor an der $\mathrm{Kgl}$. technischen Hochschule zu Berlin, Geh. Reg.-Rat

Erweiterter Sonderdruck

aus der Zeitschrift „DIE TURBINE“ VIII. Jahrg. 1911/12

Heft I, II, III, V, VI, VIII bis XI.

Mit 31 Abbildungen

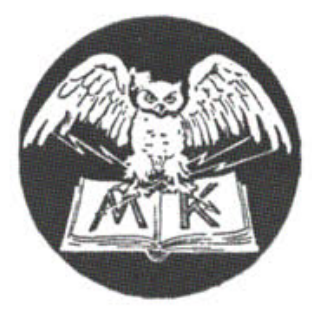

B E R LI N W

VERLAG VON M. KRAYN 
